\title{
$\mathrm{HfO}_{2}$ gate dielectric on $\left(\mathrm{NH}_{4}\right)_{2} \mathrm{~S}$ passivated (100) GaAs grown
}

\section{by atomic layer deposition}

\section{P. T. Chen ${ }^{\text {a) }}$}

Department of Materials Science and Engineering, Stanford University, Stanford, California 94305

Y. Sun

Stanford Synchrotron Radiation Laboratory, Stanford Linear Accelerator Center, Menlo Park, California 94305

E. Kim and P.C. McIntyre

Department of Materials Science and Engineering, Stanford University, Stanford, California 94305

W. Tsai and M. Garner

Intel Corporation, Santa Clara, California 95052

P. Pianetta

Stanford Synchrotron Radiation Laboratory, Stanford Linear Accelerator Center, Menlo Park, California 94305

Y. Nishi

Department of Electrical Engineering, Stanford University, Stanford, California 94305

C. O. Chui

Department of Electrical Engineering, University of California, Los Angeles, California 90095

\section{ABSTRACT}

The interface between hafnium oxide grown by atomic layer deposition and (100) GaAs treated with $\mathrm{HCl}$ cleaning and $\left(\mathrm{NH}_{4}\right)_{2} \mathrm{~S}$ passivation has been characterized. Synchrotron radiation photoemission core level spectra indicated successful removal of the native oxides and formation of passivating sulfides on the GaAs surface. Layer-bylayer removal of the hafnia film revealed a small amount of $\mathrm{As}_{2} \mathrm{O}_{3}$ formed at the interface during the dielectric deposition. Traces of arsenic and sulfur out-diffusion into the hafnia film were observed after a $450^{\circ} \mathrm{C}$ post-deposition anneal, and may be the origins for the electrically active defects. Transmission electron microscopy cross section images showed thicker $\mathrm{HfO}_{2}$ films for a given precursor exposure on S-treated GaAs versus the 
non-treated sample. In addition, the valence-band and the conduction-band offsets at the $\mathrm{HfO}_{2} / \mathrm{GaAs}$ interface were deduced to be $3.18 \mathrm{eV}$ and a range of $0.87-0.97 \mathrm{eV}$, respectively. It appears that $\mathrm{HCl}+\left(\mathrm{NH}_{4}\right)_{2} \mathrm{~S}$ treatments provide a superior chemical passivation for GaAs and initial surface for ALD deposition.

\section{INTRODUCTION}

The ever increasing need for higher speed and lower power computing has already pushed Si-based transistors close to their performance limit. Alternative materials with high carrier mobility like III-V compound semiconductors are being actively evaluated in research to supplement the present infra-structure. Bulk GaAs in particular exhibits higher electron mobility and larger bandgap as compared to $\mathrm{Si}^{1}$. However, unlike $\mathrm{Si}$, it is difficult to achieve a stable passivating native insulator by thermal oxidation and native oxides on GaAs are observed to induce high density of interface traps and cause Fermi level pinning ${ }^{2,3}$.

Recent research has resulted in different types of interfaces with high-k dielectrics that demonstrate successful III-V MOSFET devices. These include in-situ molecular beam deposited $\mathrm{Gd}_{2} \mathrm{O}_{3}{ }^{4}$, and $\mathrm{Gd}_{2} \mathrm{O}_{3}-\mathrm{Ga}_{2} \mathrm{O}_{3}$ mixtures, ${ }^{5,6}$ as well as ex-situ atomic layer deposited (ALD) $\mathrm{Al}_{2} \mathrm{O}_{3}$ or $\mathrm{HfO}_{2}$ on $\mathrm{GaAs}^{7,8}$ It was also reported that an interfacial passivation layer (IPL) such as $\mathrm{Si}^{9,10}, \mathrm{Ge}^{10}$ or $\mathrm{AlON}^{11}$ between $\mathrm{HfO}_{2}$ and $\mathrm{GaAs}$ showed improved capacitance-voltage characteristics and low leakage current. All these findings suggest that a stable and passivated interface between dielectrics and GaAs is the key component for successful GaAs MOS devices because the GaAs surface is easily degraded during the dielectric deposition. In previous studies on GaAs surface cleaning, wet chemical treatments by sulfide solutions including $\mathrm{Na}_{2} \mathrm{~S},\left(\mathrm{NH}_{4}\right)_{2} \mathrm{~S}_{\mathrm{x}}$, and $\left(\mathrm{NH}_{4}\right)_{2} \mathrm{~S}$ 
were reported to be effectively reducing the GaAs surface state density and controlling the Fermi-level position. ${ }^{12-14}$ Although several attempts ${ }^{9-11,15}$ applied sulfur treatment as a GaAs surface preparations and improved electrical performance for ALD high-k on IIIV MOS devices was reported, the bonding arrangement at the sulfide passivated interface with deposited high-k dielectrics has still not been clearly revealed.

In this paper, we report the interface bonding configuration between the $\mathrm{ALD} \mathrm{HfO}_{2}$ and the $\left(\mathrm{NH}_{4}\right)_{2} \mathrm{~S}$ passivated GaAs by using synchrotron radiation photoemission spectroscopy (SRPES) with high surface sensitivity and fine energy resolution. Upon layer by layer removal of the $\mathrm{HfO}_{2}$ film from the GaAs substrate, the compositional evolution was monitored. The topography of the GaAs surface and $\mathrm{HfO}_{2}$ film were examined via atomic force microscopy (AFM). Cross section high resolution transmission electron microscopy (HRTEM) images revealed the structure of the $\mathrm{HfO}_{2} / \mathrm{S} / \mathrm{GaAs}$ interface. In addition, the $\mathrm{HfO}_{2} / \mathrm{S} / \mathrm{GaAs}$ interface energy-band alignment was determined by monitoring offsets in the valence-band photoemission spectra.

\section{EXPERIMENT}

Epitaxial 300nm thick (Si-doped, $5 \sim 10 \times 10^{17} / \mathrm{cm}^{3}$ ) GaAs was grown by MBE on 2 inch epi-ready $n$-type (100)GaAs wafers as the starting substrates. $2 \times 2 \mathrm{~cm}^{2}$ cleaved GaAs pieces were degreased by immersing into acetone and methanol for 5 min each. The surface native oxides were removed by diluted $\mathrm{HCl}$ etching for $3 \mathrm{~min}$ and the cleaned GaAs was passivated in diluted $5 \%\left(\mathrm{NH}_{4}\right)_{2} \mathrm{~S}$ aqueous solution for $15 \mathrm{~min}$ (S-passivated GaAs). The $\mathrm{HfO}_{2}$ dielectric films were deposited on both chemically treated and nontreated GaAs pieces by 250 cycles $(\sim 20 \mathrm{~nm})$ of atomic layer deposition process at $150^{\circ} \mathrm{C}$ using $\mathrm{H}_{2} \mathrm{O}$ and tetrakisdiethylaminohafnium (TEDAH) precursors. Portions of the 
$\mathrm{HfO}_{2} /(\mathrm{S}) / \mathrm{GaAs}$ samples were ex-situ annealed in $\mathrm{N}_{2}$ ambient for 1 min at $450^{\circ} \mathrm{C}$ in an RTA chamber. The high resolution transmission electron microscopy (HRTEM) images of these dielectric stacks were obtained in a Philips CM20 FEG-TEM with samples prepared by FEI dual-beam FIB/SEM, equipped with an Omniprobe micromanipulator.

The $\mathrm{HfO}_{2}$ film was etched by 1:200 $\mathrm{HF}$ aqueous solutions in a layer by layer fashion with numerous SRPES spectra taken between these etchings. This layer-by-layer etching was carried out in an argon purged glove bag connected to the analytical loadlock of the photoemission chamber to avoid any air exposure. In order to guarantee the Spassivated GaAs surface and the $\mathrm{HF}$-etched $\mathrm{HfO}_{2}$ surfaces were smooth and without pinholes, AFM was used to monitor the surface morphology and extract root-meansquare roughness (Rrms) as a function of etching time as illustrated in Figure 1. Note that AFM was not carried out in the glove bag, so the interpretation rests on assuming that native oxide surface has similar roughness as the etched. As shown in Figure 1, the GaAs surface roughness was slightly increased after the chemical treatments, and the Rrms level during $\mathrm{HF}$ etching was maintained around $0.42 \sim 0.58 \mathrm{~nm}$ before the entire $\mathrm{HfO}_{2}$ layer was removed. The SRPES experiments were performed at beam line 8-1 and 10-1 of Stanford Synchrotron Radiation Laboratory (SSRL). Beam line 8-1 has a photon monochromatic energy range from $30-190 \mathrm{eV}$, where the $\mathrm{Ga} 3 d$, As $3 d$, Hf $4 f$ and the valence-band (VB) spectra at $120 \mathrm{eV}$ were taken. Beam line 10-1 has a photon energy range from $210-800 \mathrm{eV}$, allowed the $\mathrm{S} 2 p$ core level spectra taken at $260 \mathrm{eV}$ to be studied. The photoemission spectra were measured with a PHI model 10-360 hemispheric capacitor electron energy analyzer with the Omni Focus III small-area lens mounted on the chamber with an angle of $54^{\circ}$, with respect to the incoming photon beam direction. 
The spectra collected were fitted with a Voigt function, which is a Gaussian-broadened Lorentzian line shape. The deconvolution parameters are listed in Table 1.

\section{RESULTS AND DISCUSSION}

\section{A. GaAs surface characterization}

The first objective of this work is to evaluate the GaAs surface after chemical cleaning and passivation. As displayed in Figure 1, the GaAs surface roughness slightly increases from $0.28 \mathrm{~nm}$ to $0.31 \mathrm{~nm}$ after $\mathrm{HCl}+\left(\mathrm{NH}_{4}\right)_{2} \mathrm{~S}$ treatments due to the etching of GaAs in the $\left(\mathrm{NH}_{4}\right)_{2} \mathrm{~S}$ solution. The Ga $3 d$ and As $3 d$ SRPES spectra of GaAs samples taken at a photon energy of $120 \mathrm{eV}$, including (a) $\mathrm{HCl}$ cleaned (in an Ar ambient), (b) $\mathrm{HCl}+\left(\mathrm{NH}_{4}\right)_{2} \mathrm{~S}$ treated, and (c) $\mathrm{HCl}+\left(\mathrm{NH}_{4}\right)_{2} \mathrm{~S}+$ vacuum annealing $\left(400{ }^{\circ} \mathrm{C}\right)$ are shown in Figure 2. In Figure 2(a), the $\mathrm{HCl}$ cleaning performed in an argon (Ar) ambient leaves an oxide free GaAs surface, where Ga-O bonding, given a $0.85 \mathrm{eV}$ shift to lower kinetic energy (KE) from bulk GaAs peak, ${ }^{16}$ does not appear. Meanwhile, on the surface arsenic sites, a calculation using the equation by Carlson and McGuire ${ }^{16,} 17$ yields a 0.8 monolayer (ML) elemental arsenic layer formed on top of the GaAs surface with a chemical shift of $0.58 \mathrm{eV}$ to lower KE. No evidence of As-O bonding is observed in the

measured chemical shifts ${ }^{18}$. The spectra after $\mathrm{HCl}+\left(\mathrm{NH}_{4}\right)_{2} \mathrm{~S}$ treatments are illustrated in Figure 2(b), where the sulfide bonding on the GaAs is clearly shown. In the spectra, two different Gallium sulfides are observed. One has a $0.69 \mathrm{eV}$ shift (a gallium rich sulfide, $\mathrm{Ga}_{\mathrm{x}}-\mathrm{S}, \mathrm{x}>1$ ) with a $0.5 \mathrm{ML}$ coverage, and another has a $1.72 \mathrm{eV}$ shift (a sulfur rich sulfide, Ga-S $\mathrm{x}, \mathrm{x}>1$ ) with a $0.9 \mathrm{ML}$ on top of GaAs surface. For the As $3 d$ spectra shown in lower Figure 2(b), the elemental arsenic generated after $\mathrm{HCl}$ cleaning appears to dissolve in the $\left(\mathrm{NH}_{4}\right)_{2} \mathrm{~S}$ solution while the newly formed passivation prevents the generation of new 
elemental As. Instead, the arsenic sulfide (As-S) which has an energy shift of $1.44 \mathrm{eV}$ to the lower KE and a thickness of 0.6 ML appears to cover on the GaAs surface. Both the deconvoluted spectra of the Ga $3 d$ and As $3 d$ suggest a sulfide passivated GaAs surface without re-oxidation. In Figure 2(c), an in situ 15 min annealing at $400^{\circ} \mathrm{C}$ on the chemically treated samples in the SRPES vacuum chamber $\left(\sim 4 \times 10^{-9}\right.$ torr $)$ shows some difference. First, the elemental As is thermally desorbed and leaves a tiny trace of the signal in As $3 d$ spectrum. Besides, no trace of As-S could be resolved after the annealing. On the other hand, it appears that the intensity ratio of gallium rich sulfide $\left(\mathrm{Ga}_{x}-\mathrm{S}\right)$ to sulfur rich sulfide $\left(\mathrm{Ga}-\mathrm{S}_{\mathrm{x}}\right)$ increases after the annealing. These results suggest that $\mathrm{Ga}_{\mathrm{x}}-\mathrm{S}$ is most thermally stable which is inconsistent with the earlier observations from Sugahara ${ }^{19}$ and Spindt ${ }^{20}$. These authors argued that the annealed S-passivated GaAs will leave a gallium rich sulfide terminated surface and the As-S overlayer on GaAs is not completely desorbed until after $250^{\circ} \mathrm{C}$ anneal.

\section{B. $\mathrm{HfO}_{2} / \mathrm{S} / \mathrm{GaAs}$ interface characterization}

As described previously, the instability of sulfides on GaAs surface may affect $\mathrm{HfO}_{2}$ deposition at $150^{\circ} \mathrm{C}$. In order to trace the compositional and chemical evolution within the $\mathrm{HfO}_{2} / \mathrm{S} / \mathrm{GaAs}$ stack, a layer-by-layer wet etching of the $\mathrm{HfO}_{2}$ film was performed. A $260 \mathrm{eV}$ input photon energy was selected to detect all core level spectra of interest simultaneously with the same system settings. A fixed HF etching period of $3 \mathrm{sec}$ was used, and part of the etching profile was focused in $234 \pm 4 \mathrm{eV} \mathrm{KE}$ region ( $\mathrm{Ga} 3 d$ and Hf $4 f$ photoemission features), as illustrated in Figure 3(a). In Figure 3(a), the spectra were first aligned with the $\mathrm{Hf} 4 f_{7 / 2}$ peak obtained from the $\mathrm{HfO}_{2}$ around $235 \mathrm{eV}$ before etching. Qualitatively, the Ga $3 d$ core level spectrum hardly appears before the sample 
had been etched for $\sim 194 \mathrm{sec}$, which corresponds to the removal of $\mathrm{HfO}_{2}$. Beyond this point, the Ga-As bulk signals were strong enough to be resolved, since the inelastic mean-free paths (IMFPs) ${ }^{21}$ of Ga $3 d$ core level electrons are 5.6 5.8 $\AA$ in this KE range. Moreover, no trace of As $3 d$ and S $2 p$ spectra (not shown) were observed until $194 \mathrm{sec}$ etching.

The detail scanned spectra of the interfacial elements, including Ga $3 d / \mathrm{Hf} 4 f$ and As $3 d$ are plotted in Figure 3(b) and (c), respectively. In Figure 3(b), in addition to the Hf-O bonding contributed from the residual thin $\mathrm{HfO}_{2}$ film, the deconvoluted spectra of $\mathrm{Hf} 4 f$ also suggests a Hf-F signal with a $1.01 \mathrm{eV}$ chemical shift to lower KE. This Hf-F bonding was confirmed in a smaller electron emission angle experiment on the $170 \mathrm{sec}$ etched $\mathrm{Hf}$ $4 f$ spectrum (not shown) that showed an overlayer of hafnium fluoride covers on the $\mathrm{HfO}_{2}$ after the $\mathrm{HF}$ etching. For the interfacial gallium bonding, the gallium sites appear to remain passivated by both $\mathrm{Ga}_{\mathrm{x}} \mathrm{S}$ (larger ratio) and $\mathrm{Ga}-\mathrm{S}_{\mathrm{x}}$ during the ALD $\mathrm{HfO}_{2}$ deposition. However, in Figure 3(c), the interfacial arsenic sites appear to be partially reoxidized as an $\mathrm{As}_{2} \mathrm{O}_{3}$-like structure with an As $3 d$ feature shifted $3.18 \mathrm{eV}$ to lower KE. The re-oxidation may occur at arsenic sites from which sulfur desorption occurs in the $150^{\circ} \mathrm{C}$ ALD deposition with $\mathrm{H}_{2} \mathrm{O}$ oxidant. Since there is no evidence of any Hf-S or Ga-O bonding according to the interfacial SRPES spectra, we conclude that the de-passivated interfacial arsenic sites re-oxidized in the initial ALD cycles and formed an incubation $\mathrm{HfO}_{2}$ layer for the following up ALD deposition cycles.

\section{Annealing on $\mathrm{HfO}_{2} / \mathrm{S} / \mathrm{GaAs}$}

In order to evaluate the thermal effect on the $\mathrm{HfO}_{2} / \mathrm{S} / \mathrm{GaAs}$ layer stack, a 1 minute $450^{\circ} \mathrm{C}$ post deposition anneal (PDA) in the $\mathrm{N}_{2}$ ambient was performed ex-situ. Layer-by 
layer $\mathrm{HfO}_{2}$ removal by $\mathrm{HF}$ etching was performed again with the simultaneous acquisition of SRPES spectra. The photoemission etching profiles of Ga $3 d / \mathrm{Hf} 4 f$, As $3 d$, and S $2 p$ core level spectra taken at $260 \mathrm{eV}$ photon energy are shown in Figure 4. Among them, the spectra were first calibrated by the $\mathrm{Hf} 4 f_{7 / 2}$ position of the pure $\mathrm{HfO}_{2}$ around $233 \mathrm{eV}$ at $0 \mathrm{sec}$ etching time. Noticeably, as shown in Figure 4(a), a longer etching time over $235 \mathrm{sec}$ is required to etch away the $\mathrm{HfO}_{2}$ over-layer. This may result from crystallization and densification of the $\mathrm{HfO}_{2}$ film after the $450^{\circ} \mathrm{C}$ PDA as displayed later in the HRTEM image of Figure 6(b). Evidence of gallium out-diffusion is hard to observe since the Ga spectra overlap with strong $\mathrm{HfO}_{2}$ and hafnium fluoride features before the $235 \mathrm{sec}$ etching. On the other hand, since the inelastic mean-free paths (IMFPs) ${ }^{21}$ of As $3 d$ and $\mathrm{S} 2 p$ core level electrons are 7.0 7.2 $\AA$ and 5.1 5.2 $\AA$ in these KE ranges, the photoemission signals of As $3 d$ from the bulk GaAs and $\mathrm{S} 2 p$ from the interfacial sulfides should start to appear after $229 \mathrm{sec}$ etching if the $235 \mathrm{sec}$ etching corresponds to removal of $\sim 20 \mathrm{~nm} \mathrm{HfO}_{2}$. Evidently in Figure 4(b) and (c), traces of the out-diffused arsenic are observable starting from $203 \mathrm{sec}$ etching (about $3 \mathrm{~nm}$ above the interface) and a later time $\sim 208 \mathrm{sec}$ for sulfur because of its shorter IMFP. These out-diffused signals are sporadically observed between $203 \mathrm{sec}$ to $232 \mathrm{sec}$ which may be due to the limited diffusion paths locate at the partially crystallized interfacial $\mathrm{HfO}_{2}$. In Figure 4(b), it appears the out-diffused As $3 d$ signals are mainly attributed to Ga-As bonding because their photoemission positions are much closed to the bulk GaAs signal around $209.7 \mathrm{eV}$. It may suggest that the interface roughness or porosity lead to the simultaneous detection of substrate Ga-As signal under $\mathrm{HfO}_{2}$. In Figure 4(c), other than the sulfides, there is no 
trace of the out-diffused pure sulfur atoms which are expected to have photoemission signal at $86 \mathrm{eV} \mathrm{KE}$ range.

Detailed scanned spectra of the annealed interface, including Ga $3 d / \mathrm{Hf} 4 f$, and As $3 d$ taken after $235 \mathrm{sec}$ etching are plotted in Figure 5(a) and (b), respectively. An extra As $3 d$ spectrum after 208 sec etching for the out-diffused arsenic bonding is illustrated in Figure 5(c). In Figure 5(a), the deconvoluted bonding configuration of the interfacial gallium and the over-layered $\mathrm{HfO}_{2}$ film after anneal is similar to that in Figure 3(b) except the decreasing amount of sulfur rich gallium sulfide $\left(\mathrm{Ga}-\mathrm{S}_{\mathrm{x}}\right)$ which might be thermally out-diffused to $\mathrm{HfO}_{2}$ film. There is still no sign of gallium re-oxidation in the interface even after the PDA. Quantitatively, decreasing As-S bonding can be observed in Figure 5(b) as compared with Figure 3(c). Simultaneously, a larger amount of $\mathrm{As}_{2} \mathrm{O}_{3}$ present at the dielectric interface demonstrates the bonding changes at the depassivated arsenic after anneal. Furthermore, as shown in Figure 5(c), other than the Ga-As signal which may be contributed from the rough GaAs interface as described previously, the deconvoluted As $3 d$ spectrum indicates that the out-diffused arsenic has several bonding configurations, including the diffusion by itself as the elemental arsenic, and the formation of the non-stoichiometric arsenic oxides $\left(\mathrm{As}_{\mathrm{x}} \mathrm{O}_{\mathrm{y}}\right)$ with the oxygen ambient.

The cross-section high resolution transmission electron microscopy (HRTEM) images of these $450^{\circ} \mathrm{C}$ annealed structures are illustrated in Figure 6. In Figure 6(a), the 250 cycles of $\mathrm{ALD} \mathrm{HfO}_{2}$ was deposited on an as received (100) GaAs substrate. A layer of native oxides with $2 \sim 3 \mathrm{~nm}$ thickness at the dielectric interface, and a largely amorphous $\mathrm{HfO}_{2}$ film with a thickness of $19 \mathrm{~nm}$ is resolved. Figure 6(b) demonstrates the physical structure of the ALD $\mathrm{HfO}_{2}$ deposited on S-passivated (100) GaAs. A $22 \mathrm{~nm}$ 
thick $\mathrm{HfO}_{2}$ film covers on a $1 \sim 3 \mathrm{ML}$ of sulfur transition region in between $\mathrm{HfO}_{2}$ and GaAs suggests successful native oxides removal and the effective chemical passivation of GaAs interface. In addition, the partially crystallized $\mathrm{HfO}_{2}$ film after $450^{\circ} \mathrm{C}$ annealing is observed and can be the possible diffusion paths responsible for out-diffusion of the arsenic and sulfur which were previously observed in Figure 4.

\section{Interface energy-band alignment}

For better device scaling potential in terms of low gate leakage current, the dielectric layer is required to have sufficient barrier heights for both electron and hole injection. In the SRPES technique, the monitored offsets in the valence-band spectra can be utilized to map out the energy-band alignment ${ }^{22,23}$ for the interface between deposited ALD $\mathrm{HfO}_{2}$ and the passivated GaAs. In order to have an accurate valence-band edge measurement, the energy shift induced by the surface charging during photoemission should be corrected by aligning to the Ga $3 d$ core level peak. In Figure 7(a), the deconvoluted SRPES spectrum of a $75 \mathrm{sec} \mathrm{HF}$ etched $\mathrm{ALD} \mathrm{HfO}_{2}(\sim 10 \mathrm{~nm}) / \mathrm{S} / \mathrm{GaAs}$ was first referenced to the bulk Ga-As peak from a clean bulk GaAs taken at $120 \mathrm{eV}$. The clean bulk GaAs sample was prepared from the $\mathrm{HCl}$ cleaned (100) GaAs substrate which was in situ heated to $400^{\circ} \mathrm{C}$ for 15 min in the SRPES analytical high vacuum chamber to desorb any surface oxides and elemental $\operatorname{arsenic}^{16}$. The corresponding binding energy $\left(E_{B}\right)$ was calculated using the equation of $E_{B}=h v-E_{K I N}-\Phi_{\text {analyzer }}+\Delta_{\text {Calibration }}$, which the $\Delta_{\text {calibration }}$ is the previously aligned energy deviation from Figure 7(a). After calibrating the valence-band spectra with corrected binding energies, the valence-band offset $\left(\Delta E_{V}\right)$ between the bulk GaAs and $\mathrm{HfO}_{2}$ was found to be $3.18 \mathrm{eV}$ as highlighted in Figure 7(b). The $\mathrm{HfO}_{2} / \mathrm{S} / \mathrm{GaAs}$ interface energy-band alignment was then constructed as 
shown in Figure 8. Taking the measured energy-band gap of ALD deposited $\mathrm{HfO}_{2}\left(\mathrm{E}_{G}^{\mathrm{HO}_{2}}\right)$ to be 5.51 to $5.61 \mathrm{eV},{ }^{24}$ and together with the GaAs energy-band gap $\left(E_{G}^{G a A s}\right)$ as $1.46 \mathrm{eV}$ at $300 \mathrm{~K},{ }^{25}$ the conduction-band offset $\left(\Delta E_{C}\right)$ was deduced to be $0.87-0.97 \mathrm{eV}$.

\section{CONCLUSIONS}

The bonding configurations of the chemically treated (100) GaAs surface and the ALD $\mathrm{HfO}_{2} / \mathrm{GaAs}$ interface have been characterized by synchrotron radiation photoemission spectroscopy. Detailed core level spectra fittings indicated successful removal of the native oxides and formation of $\sim 1 \mathrm{ML}$ thick sulfides on the GaAs surface. The thermal instability of the passivating sulfides played an important role for the $\mathrm{HfO}_{2} / \mathrm{GaAs}$ interfacial bonding rearrangement during the dielectric deposition.

Layer-by-layer removal of the hafnia film revealed no re-oxidation of gallium but small amount of $\mathrm{As}_{2} \mathrm{O}_{3}$ formed at the interface during ALD deposition. Traces of arsenic and sulfur diffusion into $\mathrm{HfO}_{2}$ were observed from $3 \mathrm{~nm}$ above the GaAs surface after $450^{\circ} \mathrm{C}$ PDA, and could be the origins of electrically-active defects. Transmission electron microscopy cross section images showed thicker $\mathrm{HfO}_{2}$ on the S-passivated $\mathrm{GaAs}$ versus the non-treated sample under the same ALD deposition conditions. It also verified the $\mathrm{HfO}_{2}$ film on S-passivated GaAs after $450^{\circ} \mathrm{C}$ PDA was partially crystallized which may be the paths for the out-diffusion.

In addition, the energy-band diagram of the annealed $\mathrm{HfO}_{2} / \mathrm{S} / \mathrm{GaAs}$ structure was constructed by monitoring the valence-band offsets in the SRPES spectra. The valenceband and the conduction-band offsets have been deduced to be $3.18 \mathrm{eV}$ and a range of 0.87-0.97 eV, respectively. It appears that these treatments provide a superior chemical passivation for GaAs and initial surface for ALD deposition. 


\section{ACKNOWLEDGMENTS}

This research is supported by funds given by Intel Corp. Portions of this research were carried out at the Stanford Synchrotron Radiation Laboratory, a national user facility operated by Stanford University on behalf of the U.S Department of Energy, Office of Basic Energy Sciences. The authors would like to thank to Prof. James Harris, Dr. Zhi Liu and Donghun Choi for their assistance.

\section{Figures Captions}

Figure $1 \quad \mathrm{HfO}_{2} / \mathrm{S} / \mathrm{GaAs}$ sample surface root-mean-square roughness (Rrms) measured by atomic force microscopy (AFM) as a function of the etch time in 200:1 aqueous HF solution.

Figure 2 Deconvoluted SRPES Ga $3 d$ and As $3 d$ spectra of the GaAs surface with (a) $\mathrm{HCl}$ cleaned, (b) $\mathrm{HCl}$ cleaned $+\left(\mathrm{NH}_{4}\right)_{2} \mathrm{~S}$ passivated, (c) $\mathrm{HCl}$ clean $+\left(\mathrm{NH}_{4}\right)_{2} \mathrm{~S}$ passivation $+400^{\circ} \mathrm{C} 15 \mathrm{~min}$ in situ vacuum anneal.

Figure 3 (a) Evolution of the Ga $3 d / \mathrm{Hf} 4 f$ core-level SRPES spectra as a function of wet-etching time on the as deposited $\mathrm{HfO}_{2} / \mathrm{S} / \mathrm{GaAs}$ stack taken at a photon energy of $260 \mathrm{eV}$. Deconvoluted interfacial core-level SRPES spectra of (b)

Ga 3d/Hf $4 f$, (c) As $3 d$ taken after 194 sec of HF etching.

Figure 4 Evolution of the (a) Ga $3 d / \mathrm{Hf} 4 f$, and (b) As $3 d$, and (c) S $2 p$ core-level SRPES spectra as a function of wet-etching time for the $450^{\circ} \mathrm{C}$ annealed $\mathrm{HfO}_{2} / \mathrm{S} / \mathrm{GaAs}$ stack taken at a photon energy of $260 \mathrm{eV}$.

Figure 5 Deconvoluted interfacial core-level SRPES spectra of (a) Ga $3 d / \mathrm{Hf} 4 f$, (b) As $3 d$ taken after $235 \mathrm{sec}$ of $\mathrm{HF}$ etching on the $450^{\circ} \mathrm{C}$ annealed $\mathrm{HfO}_{2} / \mathrm{S} / \mathrm{GaAs}$ 
stack. (c) As $3 d$ SRPES spectrum for the out-diffused Arsenic taken after 208sec of HF etching.

Figure 6 The cross-section high resolution transmission electron microscopy (HRTEM) images of the $450^{\circ} \mathrm{C}$ annealed (a) $\mathrm{HfO}_{2} /$ native oxide/GaAs stack, (b) $\mathrm{HfO}_{2} / \mathrm{S} / \mathrm{GaAs}$ stack

Figure 7 (a) SRPES spectra for the $75 \mathrm{sec} 1: 200 \mathrm{HF}$ etched $(\sim 10 \mathrm{~nm}) \mathrm{HfO}_{2} / \mathrm{S} / \mathrm{GaAs}$ aligned from a clean bulk GaAs. (b) Calibrated valence-band photoemission spectra and deduced valence band offset.

Figure 8 Energy-band diagram of $\mathrm{HfO}_{2} / \mathrm{S} / \mathrm{GaAs}$ structure inferred from the SRPES measurements. 
Table

Table 1 Fitting parameters for the $\mathrm{Ga} 3 d$, As $3 d$, and Hf $4 f$ core-level spectra. All energy in $\mathrm{eV}$. 


\section{REFERENCES}

${ }^{1}$ R. Chau, S. Datta, M. Doczy, B. Doyle, B. Jin, J. Kavalieros, A. Majumdar, M. Metz, and M. Radosavljevic, IEEE Trans. Nanotechnol. 4, 153 (2005).

${ }^{2}$ M. Hong, C. T. Liu, H. Reese, and J. Kwo, in Wiley Encyclopedia of Electrical and Electronics Engineering, edited by J. G. Webster (Wiley, New York, 1999), Vol. 19, p. 87.

${ }^{3}$ W. E. Spicer, Z. Liliental-Weber, E. Weber, N. Newman, T. Kendelewicz, R. Cao, C. McCants, P. Mahowald, K. Miyano, and I. Lindau, J. Vac. Sci.Technol. B 6, 1245 (1988).

${ }^{4}$ M. Hong, J. Kwo, A. R. Kortan, J. P. Mannaerts, and A. M. Sergent, Science 283, 1897 (1999).

${ }^{5}$ M. Hong, M. Passlack, J. P. Mannaerts, J. Kwo, S. N. G. Chu, N. Moriya, S. Y. Hou, and V. J. Fratello, J. Vac. Sci. Technol. B 14, 2297 (1996).

${ }^{6}$ J. Kwo, D. W. Murphy, M. Hong, R. L. Opila, J. P. Mannaerts, A. M. Sergent, and R. L. Masaitis, Appl. Phys. Lett.75, 1115 (1999)

${ }^{7}$ P. D. Ye, B. Yang, K. K. Ng, J. Bude, G. D. Wilk, S. Halder, and J. C. M.Hwang, Appl. Phys. Lett. 86, 063501 (2005).

${ }^{8}$ M. M. Frank, G. D. Wilk, D. Starodub, T. Gustafsson, E. Garfunkel, Y. J.Chabal, J. Grazul, and D. A. Muller, Appl. Phys. Lett. 86, 152904 (2005).

${ }^{9}$ S. Koveshnikov, W. Tsai, I. Ok, J. C. Lee, V. Torkanov, M. Yakimov, and S. Oktyabrsky, Appl. Phys. Lett. 88, 022106 (2006).

${ }^{10}$ H.-S. Kim, I. Ok, M. Zhang, T. Lee, F. Zhu, L. Yu, and J.C. Lee, Appl. Phys. Lett. 89, 222903 (2006).

${ }^{11}$ M. Zhu, C.-H. Tung, and Y.-C. Yeo, Appl. Phys. Lett. 89, 202903 (2006).

${ }^{12}$ H. Sugahara, M. Oshima, H. Oigawa, H. Shigekawa, and Y. Nannichi, J.Appl. Phys. 58, 2225 (1991).

${ }^{13}$ J. Szuber, E. Bergignatb, G. Hollingerb, A. Polakowskaa, and P. Koscielniaka, Vacuum 67, 53 (2002).

${ }^{14}$ C. J. Spindt, R. S. Besser, R. Cao, K. Miyano, C. R. Helms, and W. E. Spicer, J. Vac. Sci. Technol. B, 7, 2466 (1989). 
${ }^{15}$ G. K. Dalapati, Y. Tong, W.-Y. Loh, H. K. Mun, and B.J. Cho, IEEE Trans. On Elec. Devices, 54 (8), 1831 (2007)

${ }^{16}$ Z. Liu, Y. Sun, F. Machura, P. Pianetta, W.E. Spicer, R.F.W. Pease, J. Vac. Sci. Techol. A 21(1), 212(2003)

${ }^{17}$ T. A. Carlson and G. E. McGurie, J. Electron Spectrosc. Relat. Phenom. 1, 161(1972/1973)

${ }^{18}$ P. Pianetta, I. Lindau, C.M. Garner, and W.E. Spicer, Phys. Rev. B 18, 2792(1978)

${ }^{19}$ H.Sugahara, M. Oshima, H. Oigawa, H. Shigekawa, and Y. Nannichi, J. Appl. Phys. 69, 4349(1991).

${ }^{20}$ C. J. Spindt, and W.E. Spicer, Appl. Phys. Lett. 55,1653(1989)

${ }^{21}$ NIST Electron Inelastic-Mean-Free-Path Database 71 (Ver. 1.1), National Institute of Standards and Technology, 2000.

${ }^{22}$ C.O. Chu, D.-I Lee, A.A. Singh, P.A. Pianetta, and K.C. Saraswat, J. Appl. Phys. 97, 113518(2005).

${ }^{23}$ K.-I. Seo, D.-I. Lee, P. Pianetta, H. Kim, K. C. Saraswat, and P.C. McIntyre, Appl. Phys. Lett. 89, 142912 (2006)

${ }^{24}$ N.V. Nguyen, S. Sayan, I. Levin, J.R. Ehrstein, etc. , J. Vac. Sci. Techol. A, 23 (1706) 2005

${ }^{25}$ S.M. Sze, Physics of Semiconductor Devices, $2^{\text {nd }}$ ed. (Wiley, New York, 1981) 
Figure 1

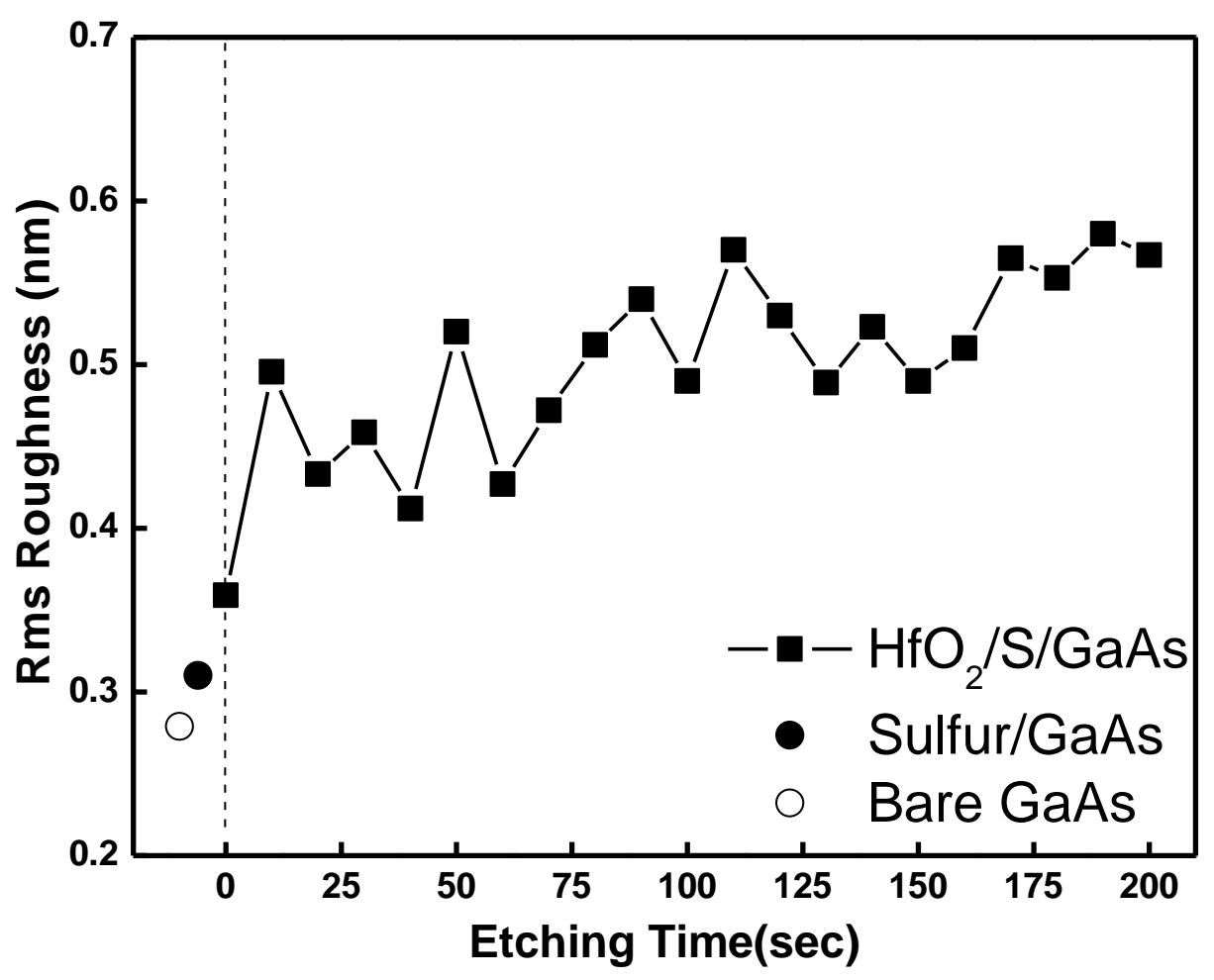


Figure 2

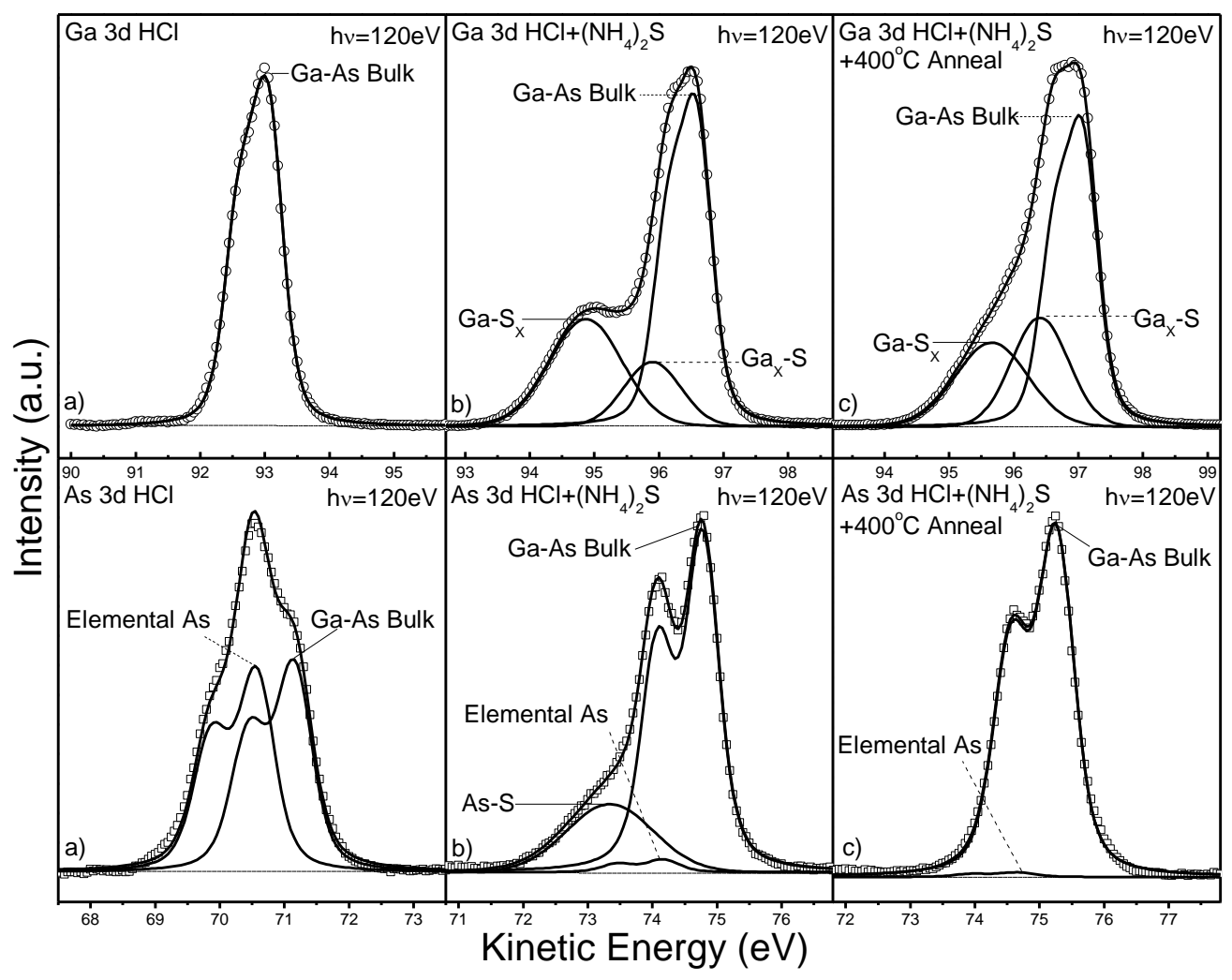


Figure 3
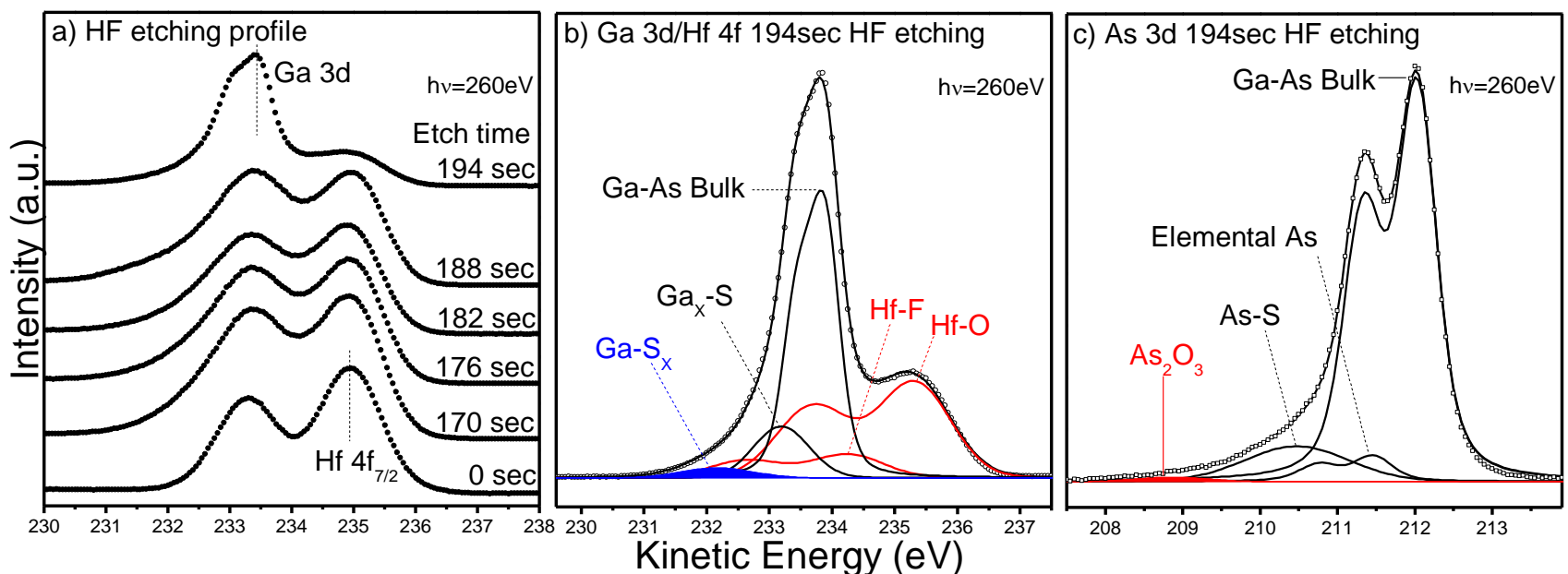
Figure 4

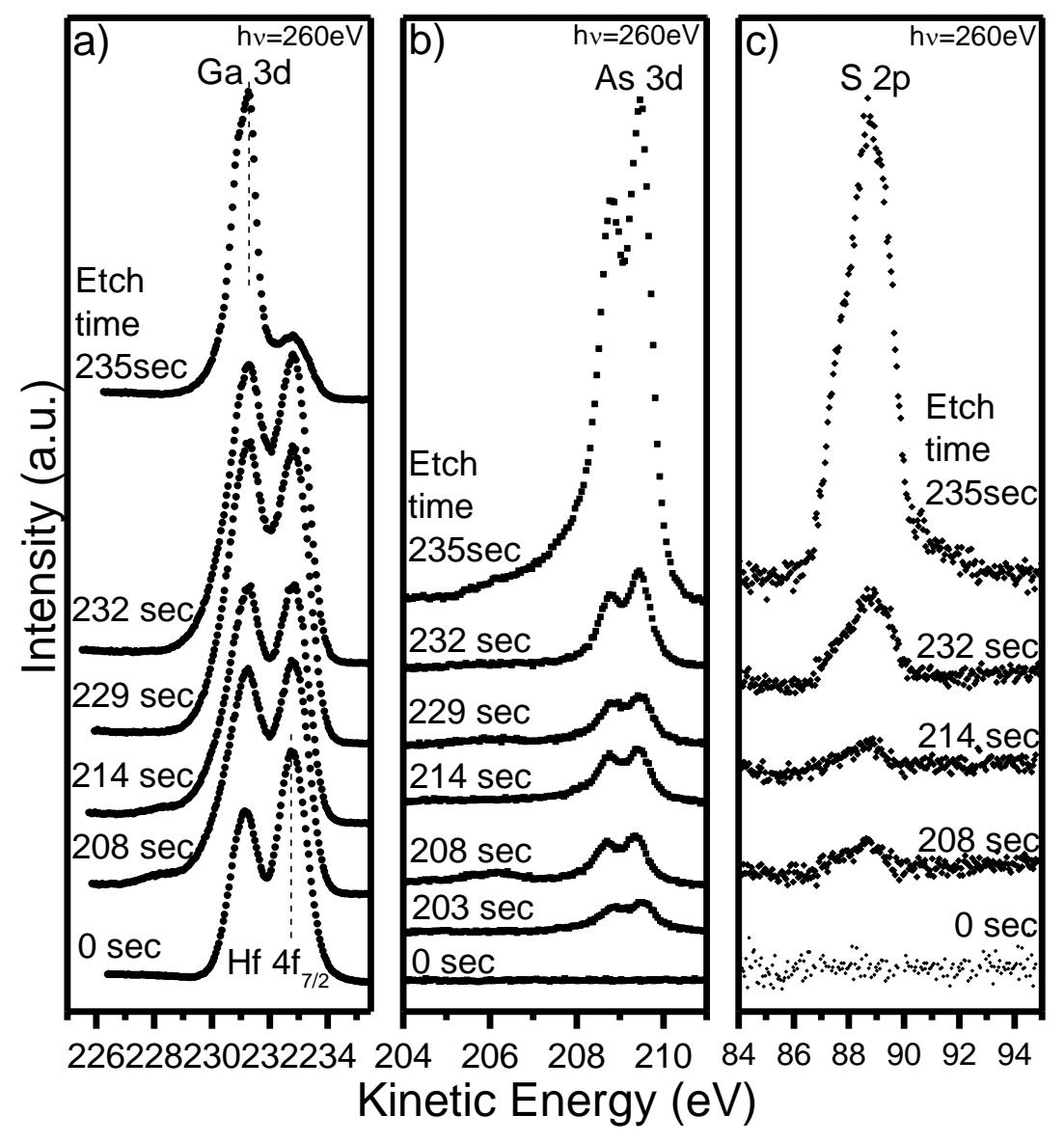


Figure 5
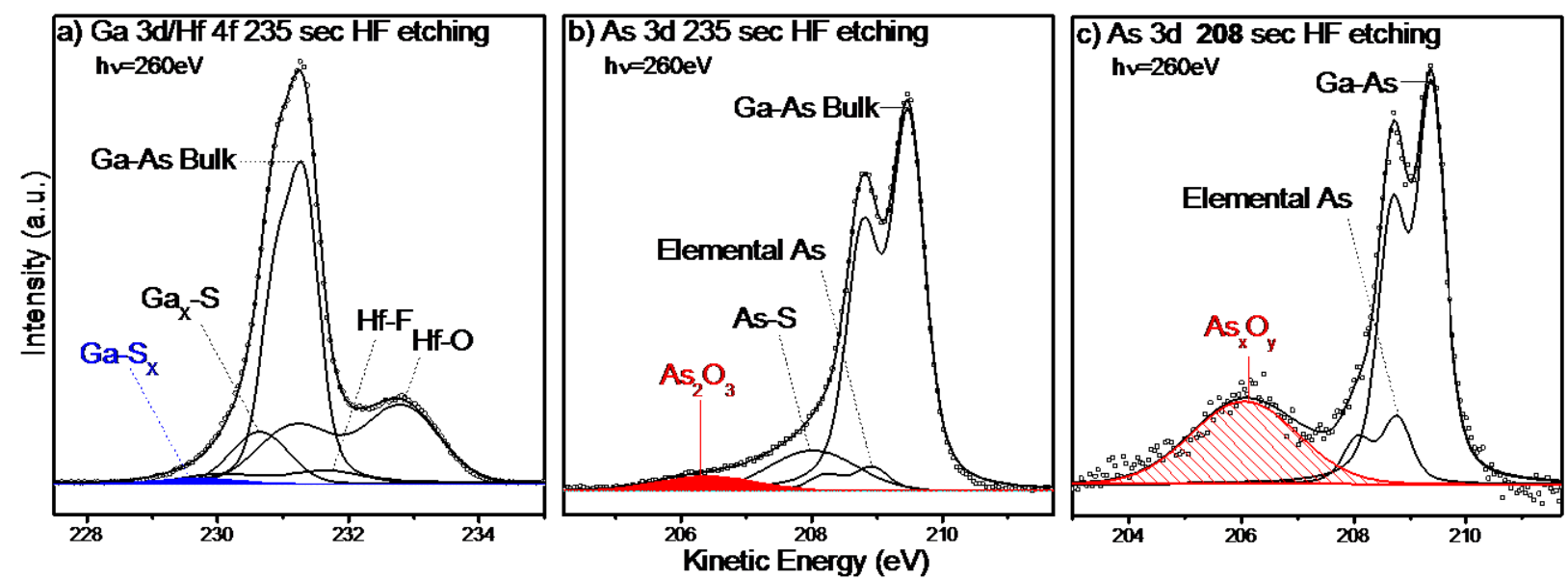
Figure 6

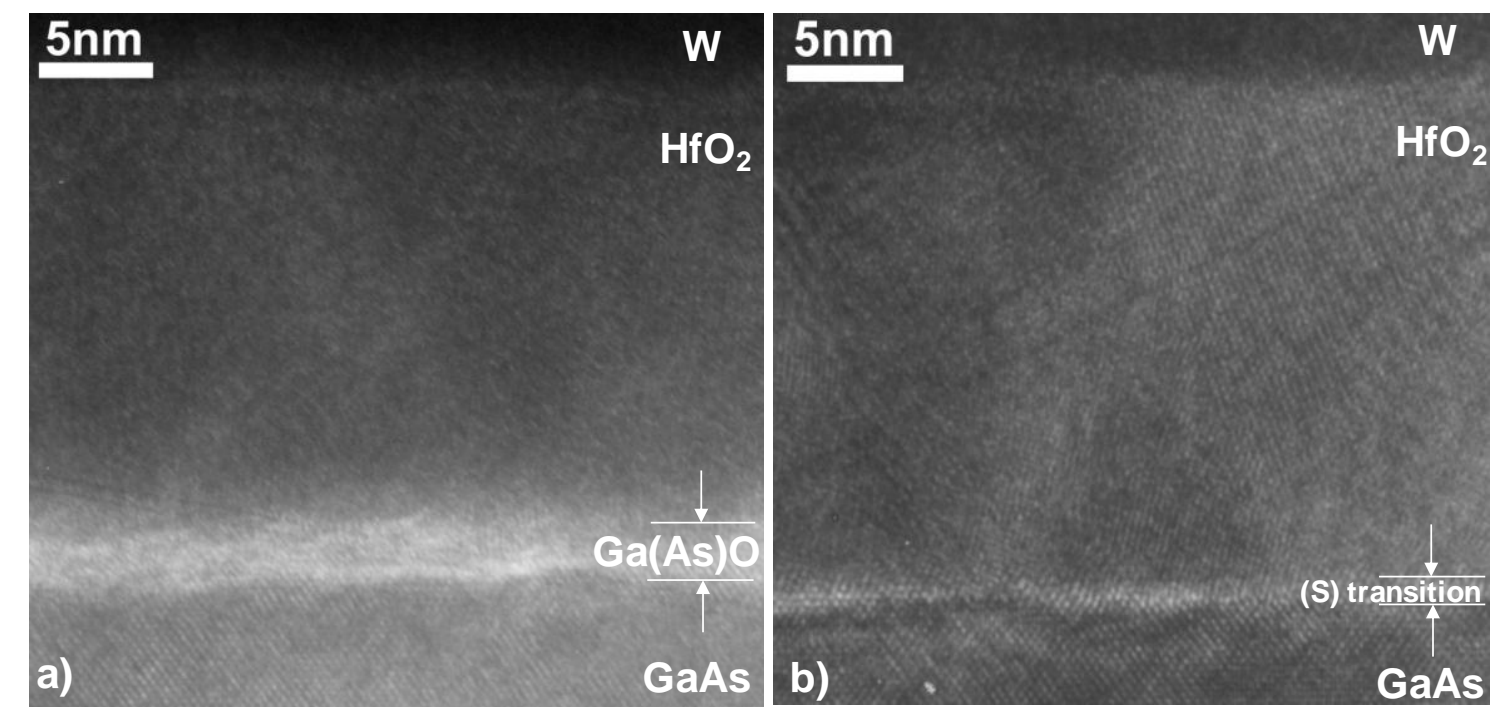


Figure 7

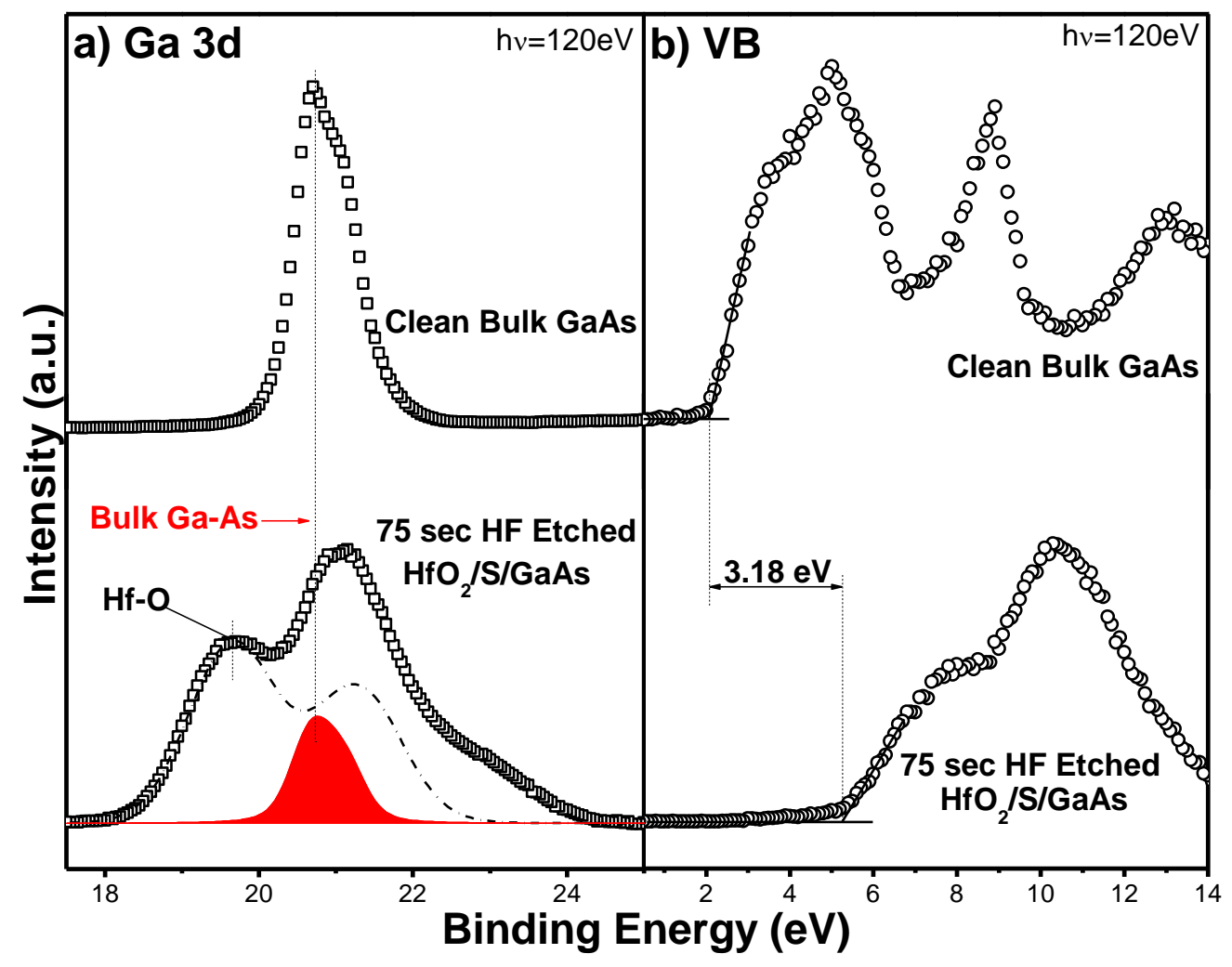


Figure 8

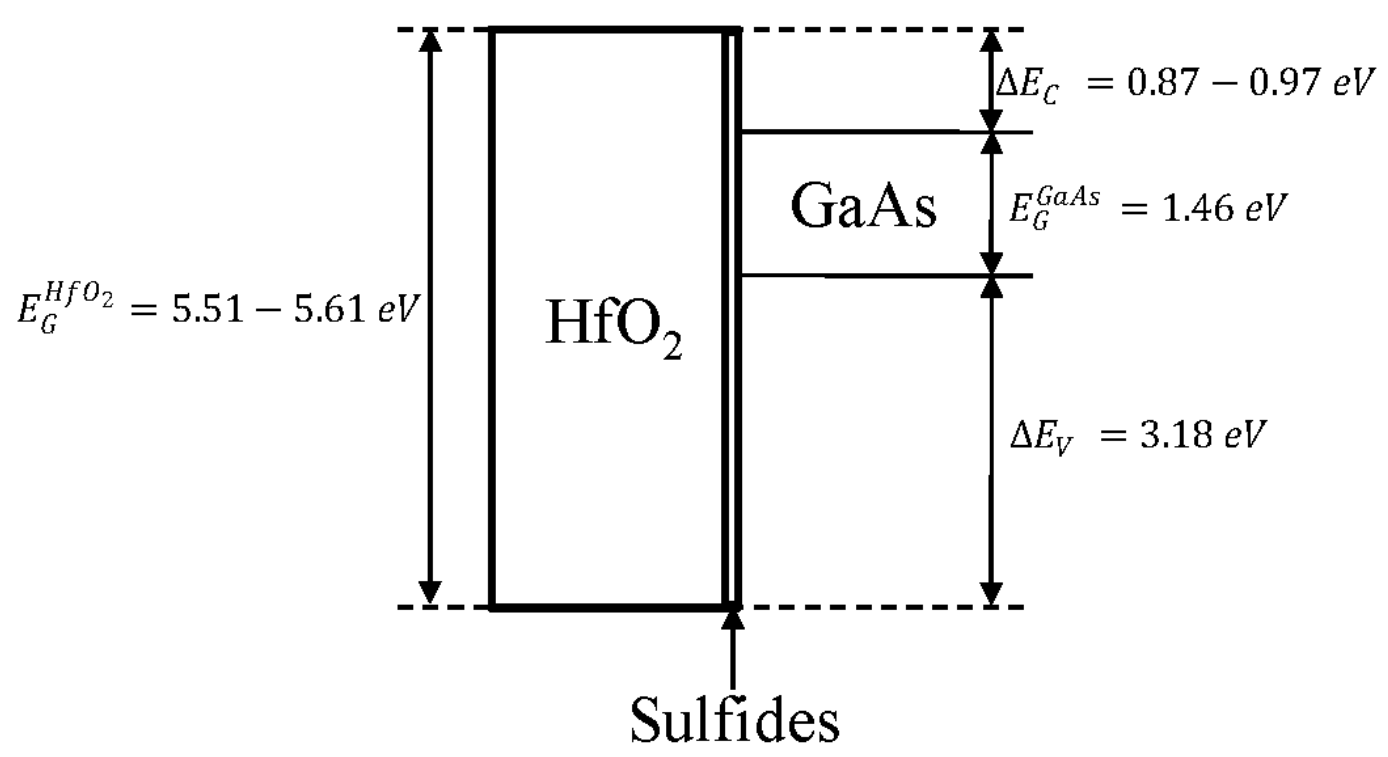


Table 1

\begin{tabular}{|l|lll|}
\hline \multicolumn{1}{|l}{ Ga $3 d$} & As $3 d$ & Hf $4 f$ \\
\hline Spin-orbit splitting & 0.44 & 0.70 & 1.62 \\
Branching ratio & 1.50 & 1.50 & 1.33 \\
Gaussian width & $0.44 \pm 0.01$ & $0.46 \pm 0.03$ & $1.15 \pm 0.02$ \\
Lorentzian width & 0.18 & 0.27 & 0 \\
\hline
\end{tabular}

